\title{
Analizando la función de la comunidad en el sistema de organización social de los cuidados en Euskadi
}

\author{
Martin Zuñiga Ruiz de Loizaga \\ Universidad de Deusto \\ martin.zuni@deusto.es
}

\author{
Felix Arrieta Frutos \\ Universidad de Deusto \\ felix.arrieta@deusto.es
}

\begin{abstract}
Europako ongizate-sistemek, batik bat meditarrenear eremukoek, errealitate demografiko eta sozial berriak eragiten dituen zaintza-eskariei behar bezala erantzuteko zailtasun nabarmenak dituzte. Euskal gizarteak, zahartze-tasa altua eta tradizio familiarista nabarmena izanda, egoera horri posizio konplexu batetik aurre egiten dio. Gaur egungo zainketen gizarte-antolaketaren eredua ordaindu gabeko emakumeen lanean oinarritzen da, gizartezerbitzuek partaidetza urria dutena, eta etxeko enplegu-pribatizazioa gero eta nabarmenagoa; azken batean, eredu horrek egoera zaila irudikatzen du. Publikoaren eta pribatuaren, Estatuaren eta merkatuaren arteko logikak, diskurtsoaren eta iruditeria kolektiboaren hegemonia dakar, baina komunitatea, arlo komunitarioa, ongizatea eta zaintza emateko hirugarren bide gisara azaleratzen da. Premisa hori oinarri hartuta, artikulu honen helburua Euskadiko pertsona adinduen zaintzaren gizarte-antolamenduko sistemetan komunitateak zein funtzio betetzen duen aztertzea da.
\end{abstract}

\section{GAKO-HITZAK:}

Zaintzak, komunitatea, zahartzea, gizartezerbitzuak, gizarte-langintza.
Los sistemas de bienestar europeos, y especialmente los de carácter mediterráneo, vienen mostrando claras dificultades para responder adecuadamente a la demanda de cuidados que la nueva realidad demográfica y social está generando. La sociedad vasca, con una alta tasa de envejecimiento y una marcada tradición familiarista, afronta esta situación desde una posición compleja. El modelo de organización social de los cuidados actual, basado en el trabajo no remunerado de las mujeres, con una escasa participación de los servicios sociales y una creciente privatización del empleo en el hogar, dibujan un escenario complicado. La lógica entre lo público y lo privado, el Estado y el mercado, hegemoniza el discurso y el imaginario colectivo, pero la comunidad, lo comunitario, emerge como una tercera vía para la provisión de bienestar y cuidados. Bajo esta premisa, este artículo tiene como objetivo analizar la función que cumple la comunidad en los sistemas de organización social del cuidado de las personas mayores en Euskadi.

\section{Palabras Clave:}

Cuidados, comunidad, envejecimiento, servicios sociales, trabajo social. 


\section{Introducción}

Los cuidados son hoy un tema de capital importancia en el debate público y político. Es evidente que la crisis de la covid-19 ha hecho emerger con toda la crudeza la necesidad de repensar el cuidado y los sistemas de organización vinculados a él. Esta realidad, no obstante, venía siendo constatada a nivel teórico desde hace al menos dos décadas, ya que los sistemas de bienestar europeos, y especialmente los de carácter mediterráneo, vienen enfrentandose a un déficit de cuidados (Tronto, 2013). Además, a esto hay que añadir el hecho de que los sistemas europeos manifiestan profundos desequilibrios demográficos, con poblaciones cada vez más envejecidas, cambios en los valores normativos de género y en la organización de las familias, y un mercado laboral cada vez más complicado que está imposibilitando que grandes grupos de personas tengan la posibilidad de cuidar y/o de ser cuidados.

Las sociedades europeas, entre ellas la vasca, afrontan esta situación desde una posición compleja. El modelo actual, basado en el trabajo no remunerado de las mujeres, con escasa participación de los servicios sociales y creciente privatización en el empleo del hogar, plantean serias dificultades para la sostenibilidad de la vida. Si a lo anterior añadimos una concepción de los cuidados como algo pertenciente al ámbito privado, a algo que las familias deben resolver con sus propios recursos, ya sea de manera directa o recurriendo al mercado, apoyado en todo o en parte con apoyos y prestaciones públicas (MorenoColom, 2019), tenemos el marco completo de la dificultad actual. En otras palabras, no está asumido socialmente ni institucionalmente que el cuidado deba ser algo resuelto democráticamente.

Ante esta situación, los sistemas de bienestar y de organización social de los cuidados demandan una reestructuración que permita dar respuesta a las necesidades emergentes, y así está ocurriendo a nivel europeo. Bajo esta premisa, crece el interés por la búsqueda de fórmulas que permitan reorganizar los esquemas de bienestar y cuidados, optimizando la función que las diferentes esferas (Estado, mercado, familia, comunidad, Tercer Sector) que participan en la provisión de bienestar y cuidados cumplen. Y, entre estas, la esfera comunitaria se erige precisamente como una de las que mayor contribución pueden hacer al respecto.

Su articulación con los sistemas de bienestar es un reto emergente, sobre el que existe un creciente interés político y académico, pero escaso desarrollo. El presente artículo expone parte de los resultados de una tesis doctoral que trata de realizar un aporte en esta dirección, poniendo el foco tanto en la función que la comunidad tiene en la provisión de cuidados, como en analizar el espacio que ocupa actualmente en el sistema de organización social de los cuidados en Euskadi.

\section{Crisis y democratización de los cuidados}

Tal y como hemos introducido, la creciente demanda de cuidados, así como el proceso de reforma institucional con tintes neoliberales y comunitaristas que se está produciendo en los sistemas de bienestar europeos, están motivando la búsqueda de nuevas formas de organizar los esquemas de bienestar y cuidado, aumentando y optimizando la función que las diferentes esferas participantes cumplen, a fin de tratar de dar una mejor respuesta a los retos que los cambios demográficos, políticos y económicos plantean. Deseados o no, estos cambios están abriendo una ventana de oportunidad para introducir una lógica progresista, democrática y comunitaria en la reforma. Si bien la lógica entre lo público y lo privado, el Estado y el mercado, hegemoniza el discurso y el imaginario colectivo, la comunidad, lo comunitario, emerge como una tercera vía para la provisión de bienestar y cuidados, lo cual rompe la lógica dicotómica arriba mencionada, proporcionando al mismo tiempo un nuevo paradigma desde el que entender la organización social, en este caso, de los cuidados.

Y pese a las dificultades a la hora de delinear qué constituye la comunidad y como lo comunitario participa en el cuidado, la coyuntura social y política está propiciando una activación de iniciativas y acciones de base ciudadana y comunitaria. Siguiendo a Moreno-Colom (2018), la comunidad emerge como un actor imprescindible ante las necesidades crecientes y el fracaso de los sistemas de bienestar actuales, y parece hacerlo, sobre todo, en los países de Europa del sur, donde la familia asume buena parte de la responsabilidad de los cuidados. En la misma línea, Durán (2017) afirma que la crisis financiera y la contracción presupuestaria de los servicios públicos han sido procesos simultáneos a la visibilización de la necesidad de organizar socialmente los cuidados. Si atendemos a la literatura especializada en los sistemas de organización del cuidado, en las últimas décadas se viene produciendo un desplazamiento desde el Estado como proveedor principal hacia el resto de esferas (Daly y Lewis, 2000), materializándose en dos grandes procesos, como son la desinstitucionalización y la privatización (Deusdad, Pace y Anttonen, 2016). El contexto de crisis económica ha hecho, en opinión de Durán (2017), más necesaria la reflexión sobre los recursos no monetizados disponibles y su potencial utilización.

La comunidad y lo comunitario resurgen con fuerza en el contexto actual, al menos a nivel discursivo, pero su articulación resulta una tarea compleja. Comasd’Argemir (2019) destaca que están surgiendo nuevas formas de redes de cuidados en contextos educativos, vecinales o locales, o entidades que con ayuda pública hacen posible incorporar voluntariado a las actividades de cuidado, aunque, pasar de la teoría a la práctica se plantea como todo un reto. El debate sobre la función y el espacio que cada esfera debe o puede tener en la provisión de cuidado es siempre complicado en 
términos técnicos, políticos e ideológicos, pero mucho más, cuando nos centramos en la esfera comunitaria. Más allá de la esfera familiar, cuando el cuidado se realiza desde la esfera pública, o desde el mercado, solemos hablar de servicios de atención. Cuando se hace desde entidades del Tercer Sector, igualmente hablamos de servicios o proyectos, pero cuando se produce en entornos sociales abiertos, sus contornos se difuminan (Vega, Martínez-Buján y Paredes, 2018). Por otra parte, sabemos que lo comunitario tiene su peso, y que el sostenimiento diario depende en mayor o menor medida de redes, vínculos y espacios en los que se cuida más allá de la familia nuclear o el entorno doméstico (Vega-Solís y Martínez-Buján, 2017). Sin embargo, no parece claro cuál es su función y cuáles son sus límites o sus confines cuando se contempla en relación a los sistemas de cuidado. Por otra parte, sus características intrínsecas - véase la espontaneidad, la informalidad, su carácter cotidiano, etc.-, hacen difícil su articulación en un marco más amplio e institucionalizado.

Además, pese al tiempo que ha transcurrido ya desde su formulación, experiencias estatales de activación comunitaria como la Big Society británica o la Sociedad Participativa en Holanda, nos han alertado de uno de los claros riesgos que entrañan las estrategias y políticas de corte comunitario. El peligro reside en que, pese a que estas fueron propuestas como estrategias de devolución de poder hacia las comunidades y los entornos locales, en la práctica, devinieron en la refamiliarización de determinados riesgos (Fine y Glendinning, 2005), y fueron cuestionadas por servir de pantalla o como eufemismo para introducir recortes y desplazamiento de responsabilidades desde la esfera pública hacia la privada (Fantova, 2014). Esto aviva el debate en torno a cuál debe ser la fórmula más correcta o efectiva para el desarrollo de estrategias comunitarias de cuidado, sin que suponga en definitiva una descarga de responsabilidades hacia las familias.

La tarea que aguarda en el momento actual es precisamente la "desfamiliarización” (EspingAndersen y Palier, 2011) de los cuidados, por lo que, además de marcar una clara diferencia entre ambas esferas, cuestión que parece simple, se deberán buscar fórmulas para hacer efectiva esta democratización, socialización o comunitarización de los cuidados. Esta tarea, no obstante, parece tener frente a sí una gran cantidad de obstáculos, algunos de los cuales son analizados en el apartado de resultados de este artículo.

Tal y como Vega, Martínez-Buján y Paredes (2018) o Moreno-Colom (2019) acertadamente recogen, con frecuencia el cuidado remite a la casa y a lo privado. Daatland (2009) nos ofrece un ejemplo de ello al afirmar que en España las responsabilidades filiales hacia el cuidado de sus progenitores son más fuertes que en el caso de un país nórdico como Noruega. Esta percepción del cuidado como una cuestión familiar y privada puede ser, como venimos sugiriendo, un elemento que genere resistencias o actúe como un obstáculo para la puesta en marcha de dinámicas de cuidado comunitarias.

En esta línea, Torns (2013) reconoce que la organización social y colectiva de los cuidados cotidianos en España debería tomar en consideración las posibles dificultades y resistencias culturales que las propuestas de socialización o comunitarización de los cuidados debieran afrontar. En este sentido, Brenner y Haaken (2000) alertan de que en el contexto socio-político actual el entorno familiar parece el único lugar en el que los individuos pueden encontrar unas relaciones no mercantilizadas y un apoyo incondicional. Esta situación puede estar produciendo una espiral descendente en la que, cuanto más se confía en la familia, más se vuelca el individuo en maximizar sus beneficios en favor de su núcleo familiar, a la vez que deja de apoyar otras personas y familias, y, en definitiva, a la comunidad.

Por otra parte, no debemos tampoco olvidar que además de resistencias culturales o de valores, existen también una serie de resistencias u obstáculos que podríamos definir como sistémicos, y que se han tratado de dejar de manifiesto al tratar la crisis de los cuidados. Nos referimos a cuestiones relacionadas con las características del mercado laboral actual, como la precarización del trabajo, la movilidad, la dificultad para la conciliación, etc. Estas características reducen el tiempo disponible para el cuidado (propio y del otro) y también para la participación social y comunitaria. En muchos casos, no es que no exista la voluntad la de cuidar, sino que, como Tobío et al. (2011) enfatizan, no es que no se quiera, sino que no se puede. De hecho, dos de las principales características de los sistemas de cuidados en las sociedades occidentales, especialmente si hablamos de la prestación de cuidados, es que se trata de un tipo de actividad no valorada socialmente y profundamente feminizada. Esto no es ninguna casualidad, ya que ambas características están interrelacionadas y han sido fundamentales para el desarrollo de un sistema productivo/reproductivo basado, hasta hace escasas décadas (y se podría argumentar que todavía hoy sigue siendo así), en la división sexual del trabajo. Este sistema solo ha sido posible gracias a una enorme "trastienda" (Prieto y Serrano, 2013), que no es otra que la del mundo de los cuidados. Tal y como recoge Rendueles (2014), nuestro sistema económico y político está enteramente construido de espaldas a la persistente realidad del cuidado mutuo. Igualmente, Herrero (2013) afirma que el sistema económico capitalista y todo el armazón cultural que le acompaña se han desarrollado en contradicción con las dependencias materiales que permiten la vida, y no solo ignoran la existencia de límites físicos en el planeta, sino que además ocultan y minusvaloran los tiempos necesarios para la reproducción social cotidiana.

No olvidemos, por tanto, como señala Zubero (2018), que para poder abordar en clave de políticas públicas la cuestión de los cuidados es imprescindible 
combatir las distintas estrategias por las que en el marco del capitalismo patriarcal se produce la invisibilización del cuidado. Esto indudablemente no será fácil, ya que, como el propio autor indica, hay intereses en juego (Zubero, 2018), y habrá personas que ganen y que pierdan según cual sea la evolución de esta lucha. Nos referimos al hecho de que cambiar el sistema de cuidados, si se hace de forma profunda, supone subvertir el statu quo. Y esto, evidentemente, encontrará resistencias desde posicionamientos ideológicos y económicos que consideran la situación actual, con sus carencias, como la más deseable.

En resumen, lo comunitario en el cuidado y su articulación con los sistemas de bienestar es un reto emergente, sobre el que existe un creciente interés político y académico, pero escaso desarrollo. En todo caso, tal y como Díaz Gorfinkel y Pérez Orozco (2011) indican, cabe señalar que en los casos en que la comunidad juega un rol, es un agente desatendido por la política pública. De manera que, aun cuando existe, su papel no se reconoce ni apoya. En línea con el pensamiento de Brenner y Haaken (2000), en lugar de centrar las políticas de cuidado en las familias, se debería hacer una apuesta por apoyar o reconstruir las comunidades e invertir en instituciones de carácter local y democráticas para la provisión de cuidados. Esto supone abordar el tema de la provisión de cuidados desde una perspectiva imaginativa, pensando en propuestas novedosas, como instituciones comunales que recojan esta expresión y visión de comunidades amigables, compasivas y democráticas.

\section{La comunidad en los sistemas de cuidados: clarificando conceptos fundamentales}

Antes de comenzar a reflexionar acerca de la función de la comunidad en los sistemas de cuidados, creemos conveniente definir o proponer una serie de planteamientos teóricos que nos sirvan como base. Concretamente, nos centraremos en dos: el primero de ellos será precisamente la conceptualización del concepto mismo de comunidad, entendido como un concepto operativo que sea de utilidad práctica; y el segundo, la estructura o esquema de los sistemas de cuidados, ofreciendo un marco interpretativo de estos.

\subsection{Un marco interpretativo para el concepto de comunidad}

Con referencia al concepto de comunidad, en un trabajo previo (Zuñiga, 2020) esbozábamos una definición de comunidad, a partir de los elementos que se destacan tras el análisis de diferentes el componente psicológico; y, la participación en actividades comunes. Con ellos hemos tratado de formular una definición provisional, operativa que pueda ser de utilidad. Así, una comunidad podría autores. Estos fueron: el territorio o espacio; los tipos ser: "Un proceso (o varios) de participación que se desarrolla en un espacio físico determinado en el que las personas y grupos que interactúan en el mismo desarrollan un componente psicológico de pertenencia/reciprocidad”.

El concepto clave de esta definición es, por tanto, la participación, una participación liminal y limitada. Se propone entender la comunidad como una realidad que requiere necesariamente participación en uno o varios procesos, y que, como resultado de ella, las personas y grupos participantes van generando elementos o componentes psicológicos identitarios o de pertenencia. Esto implica que solo serán parte de la comunidad las personas que participan en ella, lo que no quiere decir que la participación tenga que ser siempre de una intensidad o forma determinada, sino que se puede dar con muy diferentes niveles de implicación o compromiso, y ser cambiante o fluctuante a lo largo del tiempo.

La comunidad no será, por tanto, una estructura estable o inmutable; todo lo contrario, debemos pensarla como relaciones sociales que se hacen y se deshacen. La comunidad es, desde nuestro punto de vista, un proceso relacional dinámico, en constante transformación, que cuenta con unas coordenadas espacio-temporales concretas. En otras palabras, la comunidad estará formada por todas las personas que se encuentren, en un espacio y momento dados, comprometidas en la misma tarea. Estas personas están vinculadas por relaciones de amistad y vecindad que se desarrollan en sus entornos de vida habituales y se rigen por la lógica de la reciprocidad. De esta forma, no podemos equiparar comunidad a pueblo, barrio, o cualquier otra delimitación espacial, sino que en cada una de estas pueden existir varias, una o ninguna comunidad.

\subsection{La estructura de los sistemas de cuidados}

Respecto al segundo punto que quisiéramos clarificar, en primer lugar debemos señalar que los cuidados pueden abordarse desde dos planos complementarios. Daly y Lewis (2000) nos muestran cómo bajo el concepto de cuidado se esconde una realidad compleja que puede abordarse desde dos planos complementarios: el relativo al desempeño individual del rol involucrado; y el social, es decir, desde su relación con los sistemas y servicios provisionados por las diferentes instancias de la sociedad. En consecuencia, es esencial destacar que la noción de cuidado que se utiliza en este artículo va desde el ámbito micro, en el que se desarrollan prácticas sociales realizadas por personas concretas, hasta el ámbito macro, compuesto de instituciones y agentes sociales (Tobío et al., 2010). Es decir, la acción o actividad concreta de cuidado, es provista como parte o integrada en un complejo sistema.

Hasta el momento actual, el cuidado y el bienestar han sido analizados como ámbitos separados en la mayoría de estudios. La realidad es que ambos 
son provistos por medio de complejos sistemas 0 esquemas en los que intervienen diversos agentes, actores o instituciones, en lo que ha venido a ser designado como welfare mix. Ciertamente, el uso de este concepto es más habitual en el estudio de los sistemas de bienestar, pero como desarrollaremos a continuación, las esferas que participan en la provisión de bienestar y cuidados son exactamente las mismas. Podemos, por tanto, partir del concepto de welfare mix para señalar cuáles son las esferas que participan en la provisión de cuidados, ya que, en resumen, vienen a hacer referencia a una misma realidad.

Un breve repaso a la extensa literatura existente acerca de los sistemas de bienestar, así como a las diferentes políticas puestas en marcha, parece mostrar fehacientemente que no existe consenso en torno a cuáles son las esferas que conforman el concepto de welfare mix, que a pesar del énfasis, no deja de ser un cul de sac donde cada autor establece un orden y unas preferencias acordes con su punto de vista. Así, encontramos propuestas que suelen integrar tres o cuatro esferas, siendo estas designadas de diferente manera, incluso quedando unas excluidas frente a otras. Lo que queda claro es que en esta delimitación de las esferas que intervienen, la comunidad apenas es reconocida como esfera diferenciada o, cuando es identificada, suele ser agrupada como parte de otras esferas.

Actualmente, la amplia mayoría de los estudios reconocen la existencia de cuatro grandes esferas que vendrían a dibujar un diamante, pero estas varían ligeramente de un planteamiento a otro. En el análisis de la provisión de bienestar y cuidados, tanto la esfera pública, representada por el Estado, como la esfera privada, representada por el mercado, tienen prevalencia. El resto, o bien no son identificadas, 0 , cuando lo son, no se les atribuye el mismo rol. Existe por tanto un menor consenso en torno a la forma de designar y definir al resto de esferas, que en algunos casos no va más allá del plano semántico, pero que, en otros, puede implicar diferencias de mayor relevancia. Si atendemos a la literatura especializada en la materia, encontramos dos grandes grupos de esquemas, entre los que también se dan algunas divergencias. Estos dos grandes grupos son, a grandes rasgos, aquellos esquemas que no integran a la familia como una esfera en sí misma (véase, entre otros, Del Pino y Rubio, 2016; Fantova, 2014; Herrera, 2001; Llena, Parcerisa y Úcar, 2009; Maino, 2015; Oosterlynck et al., 2013; Pastor, 2001; Pestoff, 1998), y aquellos que sí lo hacen (como Daly y Lewis, 2000; Esping-Andersen, 1990; Lee, Chae y Lim, 2016; Longo, Notarnicola y Tasseli, 2015; Mažeikienė, Naujanienè y Ruškus, 2014; Razavi, 2007; RodriguezCabrero y Marbán, 2016). Los primeros han sido utilizados para el análisis de los sistemas de bienestar y los segundos, para el estudio de los sistemas de organización social de los cuidados.
La existencia de estos dos grandes grupos, con sus diferencias, reside por tanto en la naturaleza u orientación analítica de los esquemas. Por lo tanto, en función del objeto de estudio, puede interesar o no aislar o reconocer a la familia como un actor separado, o puede resultar más conveniente integrarla dentro de la esfera comunitaria, o el sector informal. Por ejemplo, debido al papel central de la familia en ámbitos como el cuidado, muchos estudios centrados en esta materia utilizan esquemas en los que se reconoce a la familia como una esfera diferenciada. No así en otra serie de conceptualizaciones, en las que la familia forma parte de un conglomerado más amplio.

Desde la perspectiva de este trabajo, se considera que ninguno de los esquemas propuestos capta con exactitud un esquema preciso y adecuado para analizar los sistemas de organización social del cuidado. Creemos necesario, por tanto, integrar las dos grandes corrientes y construir un esquema propio que ponga en valor el espacio de todas las esferas. De esta forma, planteamos que un pentágono puede ejemplificar mejor la forma en la que se articulan las diferentes esferas, ya que deberán ser cinco: el Estado, el mercado, el Tercer Sector, la comunidad y la familia.

El reparto de roles entre las diferentes esferas, es decir, el peso que cada una de ellas tenga frente a las demás en la provisión de cuidados, dará lugar a un modelo determinado de cuidados. En el contexto que nos ocupa, partimos de un escenario en el que, como en el resto de países que se reconocen como parte del régimen mediterráneo, las familias ocupan un espacio central y un alto nivel de concertación público-privada, en el que el Tercer Sector tiene también un papel importante. Sin embargo, como hemos introducido y tratamos de analizar en este trabajo, la comunidad y lo común emergen como una tercera vía para la provisión de bienestar y cuidados que rompe la lógica dicotómica, presentando un nuevo paradigma desde el que entender la existencia y la organización social, en este caso, de los cuidados. Además, el marco normativo vigente en Euskadi reconoce el enfoque comunitario de atención como enfoque de referencia para el sistema de servicios sociales, lo que establece un punto de partida favorable, aunque solo sea sobre el papel, ante la propuesta de integrar en mayor medida a las comunidades en los sistemas de cuidados.

Teniendo en cuenta todo lo expuesto, la tarea que aguarda en el momento actual es avanzar en la democratización, socialización o comunitarización de los cuidados, así como de las instituciones y administraciones que participan en la provisión y organización de estos. Esta tarea, no obstante, parece tener frente a sí una gran cantidad de obstáculos, algunos de los cuales analizaremos a continuación, así como trataremos de identificar cuáles son las fortalezas y el valor que lo comunitario aporta al cuidado, en este caso, de las personas mayores. 


\section{Metodología}

La investigación en la que se basa este artículo persigue dar respuesta a dos grandes preguntas que están, además, estrechamente relacionadas. La primera de ellas es: ¿cuál es la función que cumple la comunidad en el cuidado? Es decir, ¿qué tipo de cuidados provee? ¿Cómo los provee? ¿Con qué intensidad? Y, en segundo lugar, ¿qué espacio ocupa la comunidad en los sistemas de organización social del cuidado? Es decir, ¿qué función le otorgan la sociedad en general y los sistemas públicos de bienestar en particular? ¿Cómo se relaciona con el resto de esferas que participan en los sistemas de organización social del cuidado? Y, en especial ¿cómo se relaciona la esfera pública con la comunitaria?

\subsection{Fases y muestreo}

La investigación que se presenta en este artículo, de carácter emergente, ha contado con tres fases diferenciadas, que han sido desarrolladas cronológicamente en el orden en que a continuación se presentan. La primera de ellas, referente al proceso de cocreación, ha sido desarrollada a lo largo de un curso académico (2017-2018), mientras que el resto han sido desarrolladas a lo largo de los años 2018 y 2019 de forma menos intensiva.

Tabla 1. Fases de la investigación

\begin{tabular}{c|c|c}
\hline FASE I & FASE II & FASE III \\
\hline $\begin{array}{c}\text { Proceso de } \\
\text { cocreación }(\mathrm{n}=117)\end{array}$ & $\begin{array}{c}\text { Grupos de } \\
\text { discusión }\end{array}$ & $\begin{array}{c}\text { Entrevistas en } \\
\text { profundidad }(\mathrm{n} \\
=29)\end{array}$ \\
& $\begin{array}{l}\text { - Grupo 1 }(\mathrm{n}=5) \\
\text { Grupo 2 }(\mathrm{n}=7)\end{array}$ & \\
\hline
\end{tabular}

Fuente: Elaboración propia.

La primera fase esta investigación comprende la realización de un proceso de cocreación comunitaria, llamado Lkaleak, desarrollado en barrio de Egia de la ciudad de Donostia/San Sebastián. En este proceso, personas mayores del barrio, junto con diferentes instituciones (del sector público, del Tercer Sector, y la propia Universidad de Deusto) han asumido el protagonismo y han participado en un proceso de reflexión que tiene como objetivo último orientar las políticas de participación y envejecimiento del Ayuntamiento de Donostia-San Sebastián. Es, por tanto, un proyecto de carácter interinstitucional e interprofresional, diseñado por tres entidades: el Ayuntamiento de Donostia/San Sebastián, la Asociación para la Promoción de la Tecnología Social (Aptes) y la Universidad de Deusto.

La segunda fase del apartado empírico de este trabajo ha sido la realización de dos grupos de discusión con personas participantes en el proceso de cocreación que se acaba de describir. Como se puede ver en la Tabla 2, el primero de ellos estuvo conformado por algunas de las personas mayores que ejercieron un papel más activo en el proceso participando como coinvestigadores/as, y el segundo grupo está conformado por las personas que participaron en el diseño y el desarrollo del proyecto desde una posición profesional.

Tabla 2. Códigos y descripción de los participantes de los grupos de discusión

\begin{tabular}{|c|c|c|}
\hline & Código & Descripción \\
\hline \multirow[t]{6}{*}{ Grupo 1} & $\mathrm{G}_{1} \mathrm{M}_{1}$ & Mujer, $70+$ \\
\hline & $\mathrm{G}_{1} \mathrm{M}_{2}$ & Mujer, $70+$ \\
\hline & $\mathrm{G}_{1} \mathrm{H}_{1}$ & Hombre, 70+ \\
\hline & $\mathrm{G}_{1} \mathrm{H}_{2}$ & Hombre, $70+$ \\
\hline & $\mathrm{G}_{1} \mathrm{M}_{3}$ & Mujer, $70+$ \\
\hline & Código & Descripción \\
\hline \multirow[t]{7}{*}{ Grupo 2} & $\mathrm{G}_{2} \mathrm{M}_{1}$ & Mujer, Tercer Sector \\
\hline & $\mathrm{G}_{2} \mathrm{H}_{1}$ & Hombre, Tercer Sector \\
\hline & $\mathrm{G}_{2} \mathrm{M}_{2}$ & Mujer, Administración Pública \\
\hline & $\mathrm{G}_{2} \mathrm{M}_{3}$ & Mujer, Administración Pública \\
\hline & $\mathrm{G}_{2} \mathrm{M}_{4}$ & Mujer, Tercer Sector \\
\hline & $\mathrm{G}_{2} \mathrm{H}_{2}$ & Hombre, Universidad \\
\hline & $\mathrm{G}_{2} \mathrm{M}_{5}$ & Mujer, Tercer Sector \\
\hline
\end{tabular}

Fuente: Elaboración propia.

Para la tercera fase de la investigación, se ha realizado un muestreo intencional o no probabilístico, ya que los sujetos de la muestra no han sido elegidos siguiendo leyes del azar, sino de forma consciente e intencional (Ruiz de Olabuénaga, 2012). Siguiendo esta lógica, se han llevado a cabo un total de 29 entrevistas en profundidad (ver Tabla 3), a personas de tres perfiles: por un lado, personas con cargos de gestión relevantes designados políticamente; por otro, gestores de alta relevancia en diferentes instituciones públicas; $y$, finalmente, expertos y académicos, todos ellos con amplio conocimiento acerca del objeto de estudio. Además, se han tenido en cuenta los criterios de género, siendo 19 mujeres y 10 los hombres entrevistados, así como un número parecido de profesionales públicos (13) y expertos/as (16), y cierta representatividad de los tres territorios en lo que a profesionales de las instituciones públicas de los tres territorios de la Comunidad Autónoma de Euskadi respecta (cuatro en Bizkaia, cuatro en Gipuzkoa y cinco en Araba). Respecto al nivel institucional, han sido entrevistados profesionales de los tres ámbitos institucionales (Gobierno Vasco, diputaciones y ayuntamientos), siendo los ayuntamientos la institución de la que más profesionales se han entrevistado, por su más estrecha relación con el ámbito comunitario y los servicios sociales de atención primaria (en el anexo se puede consultar la lista completa). 
Tabla 3. Muestreo de los y las participantes en las entrevistas en profundidad

\begin{tabular}{l|c|c|c}
\cline { 2 - 4 } & Bizkaia & Gipuzkoa & Araba \\
\hline Participantes (n) & $\mathrm{n}=13$ & $\mathrm{n}=11$ & $\mathrm{n}=5$ \\
\hline Muestreo & $\begin{array}{c}\text { Cargo } \\
\text { político } \\
(\mathrm{n}=2)\end{array}$ & $\begin{array}{c}\text { Cargo } \\
\text { político } \\
(\mathrm{n}=1)\end{array}$ & $\begin{array}{c}\text { Cargo } \\
\text { político } \\
(\mathrm{n}=1)\end{array}$ \\
& $\begin{array}{c}\text { Gestor } \\
\text { público } \\
(\mathrm{n}=2)\end{array}$ & $\begin{array}{c}\text { Gestor } \\
\text { público } \\
(\mathrm{n}=3)\end{array}$ & $\begin{array}{c}\text { Gestor } \\
\text { público } \\
(\mathrm{n}=4)\end{array}$ \\
& $\begin{array}{c}\text { Experto } \\
(\mathrm{n}=9)\end{array}$ & $\begin{array}{c}\text { Experto } \\
(\mathrm{n}=7)\end{array}$ & \\
& & & \\
\hline
\end{tabular}

Fuente: Elaboración propia.

\subsection{Análisis}

La información procesada en este análisis ha sido obtenida mediante las entrevistas en profundidad y los grupos de discusión, que ha sido transcrita y analizada por medio del software Atlas.ti8. Se trata de un análisis de carácter temático, tanto por la lógica seguida para el análisis como por la forma de presentar los resultados. Inspirada por la propuesta de Kurckartz (2014), ha comprendido cinco fases diferenciadas: 1) lectura y subrayado de pasajes importantes: en este punto se identifican unidades conceptuales (o reducibles a ellas), y se realiza un proceso de “descontextualización” (Escalante, 2009) que consiste en sacar de su contexto un extracto de texto con la finalidad de hacerlo semánticamente independiente; 2) codificación inicial o abierta (lógica inductiva): a cada uno de estos pasajes o conceptos se les ha asignado un código o se ha creado un código in-vivo o emergente desde una lógica inductiva, cuando se ha considerado que representaba un tema relevante que el marco analítico deductivo no ha considerado. En total, se han identificado un total de 133 códigos inductivos; 3) clasificación de los códigos y codificación temática (lógica deductiva): estos códigos han sido posteriormente clasificados como parte de categorías superiores ya existentes que representas los grandes temas que aborda la investigación (comunidad, cuidados, contexto social y envejecimiento, sistema de servicios sociales y trabajo comunitario); 4) jerarquización y recodificación (lógica abductiva): a continuación, se ha realizado el análisis de los códigos y las categorías por cada uno de los grandes temas, agrupando la información y estableciendo relaciones y jerarquías entre los conceptos (i.e., asociaciones de personas mayores < participantes clave < claves proceso < trabajo comunitario). En esta fase, se ha reparado también a la groundedness (fundamentación) y density (densidad) de los códigos para identificar aquellos temas que adquieren una mayor relevancia, reiteración o fuerza en los discursos de las personas entrevistadas, así como su conexión con otra serie de códigos. En este punto interviene un análisis "cuantitativo" de los elementos identificados: frecuencia de aparición, variación según los hablantes, según los contextos, interdependencia entre los elementos, etc. (Escalante, 2009); 5) interpretación, abstracción y resultados: finalmente, los resultados son presentados siguiendo la lógica del análisis por temas o categorías previamente realizado. Las conclusiones, por su parte, son construidas no solo por medio del análisis, sino también, tal y como enfatiza Chowdhury (2015), teniendo en cuenta el contexto y el momento en el que se desarrolla la investigación.

\section{Resultados}

Tanto la cantidad de información analizada como los resultados obtenidos en la investigación que se presenta exceden notablemente el espacio que un artículo de estas características puede abarcar, por lo que nos limitaremos a exponer, de manera sintética, algunas de las principales ideas, organizadas en torno a los siguientes temas: la función de la comunidad como fuentes de provisión de cuidados; el espacio de la comunidad en los sistemas de organización social de los cuidados; y la comunidad en la configuración actual del sistema de servicios sociales en Euskadi. Los extractos que se presentan son los obtenidos por medio de los grupos de discusión y las entrevistas en profundidad.

\subsection{La función de la comunidad como fuente de provisión de cuidados}

Como se ha identificado a lo largo de esta investigación, el cuidado comunitario se compone de "microrelaciones", que se dan en el día a día, en la cotidianeidad. La función que la comunidad tiene en el cuidado se circunscribe al ámbito social y relacional, y a pequeños apoyos de carácter instrumental. Gardner (2011) se refiere a estas relaciones como "natural neighborhood network", que podemos traducir como la "red vecinal natural", que es aquella red de relaciones e interacciones informales que pueden mejorar el bienestar y que en ocasiones representa la práctica totalidad de la vida social de muchas personas mayores. Las personas entrevistadas señalan que lo que las personas mayores esperan recibir de la comunidad son cuestiones que pueden definirse como simples o sencillas. Se trata de pequeños gestos, como el saludo, una mirada cómplice, una conversación, etc., o guardar las llaves de casa, subir la compra, el periódico, etc.

\footnotetext{
A mí me parece que son microrelaciones. Porque la gente lo que pide es una mirada, un achuchón, microacciones que hacen que te sientas parte de. Los testimonios han sido muy valiosos porque la gente no pide grandes cosas. (Grupo discusión profesionales, $\mathrm{G}_{2} \mathrm{M}_{4}$ )
}

Pudiera parecer que muchas de estas interacciones carecen de valor por su superficialidad, pero, tal y como Sennet (2019) afirma, en este caso la 
superficialidad no sería un defecto. En opinión del autor, pese a que pueda no existir un verdadero interés en saber cómo se encuentra un vecino/a, el hecho de preguntar supone una señal de reconocimiento. Esos pequeños gestos de cortesía, que pueden ser más o menos impersonales, pueden servir para ir restableciendo una conexión social. A partir de aquí, claro está, la intensidad y cercanía deberán ir desarrollándose, dando lugar a relaciones más significativas.

Si bien estas peticiones no implican un gran esfuerzo ni movilización de recursos, se señala que pueden suponer un cambio y un apoyo importante en la vida de las personas mayores. La función de la comunidad, en especial en su dimensión relacional, se ha definido como esencial para el bienestar y la salud de las personas mayores. Tal y como sugieren nuestros resultados, esta podría tener un efecto preventivo y protector que permite que las personas sigan viviendo en su entorno de vida habitual de forma segura durante más tiempo.

Entonces le pide que le traiga el pan a no sé quién, o si van con la bolsa de la compra pues la deja en el portal y se la va a subir algún vecino cuando pase por allí. 0 sea, ese tipo de cosas que se hacen pues por la amistad y por la relación vecinal, pues permite que la gente siga en su entorno mucho más tiempo que si eso no funcionara. Entonces, el papel es esencial. (Experto/a-académico/a, MEB1)

De hecho, se ha mencionado que, en algunos casos, la comunidad puede ser la única alternativa (cargo político, MPOG1) para poder residir en el entorno de vida habitual de forma segura. En este sentido, se ha destacado también la función de antena que estas relaciones pueden tener, al servir como detectores de situaciones de cierto riesgo o vulnerabilidad. Esta "vigilancia", en su sentido más positivo, puede realizarse entre amigos/as o vecinos/as, pero también tiene un gran potencial de coordinación con la esfera mercantil (pensemos por ejemplo en kioskos o panaderías que conocen los hábitos de sus clientes y pueden detectar un cambio en sus patrones), y especialmente con las instituciones públicas, entre los que destacarían los servicios sociales, por su responsabilidad en este ámbito.

Uno de los elementos centrales de la función de la comunidad en el cuidado es el apoyo vinculado a cuestiones de carácter relacional e inmaterial, más que a otros apoyos de carácter material, que también pueden darse por medio de estas relaciones. Así, lo material suele estar cubierto en la mayoría de los casos, mientras que lo inmaterial, lo intangible, es aquello de lo que mas carecen ciertas personas mayores (aunque podríamos extenderlo a cualquier persona), y donde más efectivas son las relaciones comunitarias. Este elemento ha ido emergiendo a lo largo del análisis junto a otros códigos como amistad, cariño y amor.
La comunidad tiene por tanto un papel esencial en satisfacer necesidades emocionales, y brinda un apoyo y un acompañamiento afectivo y/o psicológico. El valor de lo comunitario es mayormente intangible, y a menudo invisible, pero su efecto a nivel emocional puede ser más determinante de lo que se podría suponer, especialmente para personas con una red social escasa. Pese a que pudieran parecer contactos o relaciones triviales, de escasa profundidad, lo cierto es que este tipo de contactos cotidianos pueden suponer los únicos contactos $y$ relaciones diarias de muchas personas.

Al respecto de la naturaleza de las relaciones comunitarias de tiempo social y acompañamiento, que pueden ser un importante apoyo, es necesario señalar que, tal y como nuestros resultados confirman, difícilmente podrán ser sustituidas por relaciones, servicios o apoyos que provengan del resto de esferas que participan en la provisión de bienestar y cuidados (al menos si lo que se buscan son relaciones significativas, en las que se construye un vínculo mediado exclusivamente por una lógica de reciprocidad).

Creo que, en general, lo que veo es que por mucho que la institución pongamos recursos, nunca vamos a llegar por nosotros solas a cubrir esos espacios de acompañamiento, el aspecto relacional que puede cubrir la comunidad. (Profesional-gestor público, FPMA2)

En conclusión, podríamos cerrar este apartado destacando que la comunidad tiene una función claramente definida en el cuidado, circunscrita al ámbito social y relacional, dando respuesta a necesidades psicológicas y emocionales, además de pequeños apoyos de carácter material. Así, la principal forma en la que este cuidado es provisto es a través de interacciones y relaciones que se establecen con diferentes grados de estabilidad e intensidad. Podemos agrupar aquí desde gestos (aparentemente) superficiales entre vecinos/as, hasta relaciones de amistad o vecindad de años de duración. A medida que las relaciones son más estables e intensas, y, en definitiva, más significativas, su potencial cuidador aumenta, lo que no es óbice para no reconocer el valor que las pequeñas interacciones, pese a su sencillez, también parecen tener. El concepto clave a este respecto es el de participación en la vida social y comunitaria, ya que es a través de esta participación que se posibilita que se den las interacciones y se establecen las relaciones.

\subsection{Definiendo el espacio de la esfera comunitaria en el sistema de organización social del cuidado}

En este artículo se ha definido la comunidad como un proceso, en contraposición a una estructura o agente con una morfología determinada y una entidad estable. A diferencia del resto de esferas, que son estructuras o instituciones fácilmente identificables, podría parecer que la definición de su espacio en 
los sistemas de cuidado es una tarea más compleja. Sin embargo, nuestro planteamiento es claro y meridiano, el espacio de la comunidad en el cuidado es aquel que ocupan relaciones primarias que van más allá del vínculo de parentesco, y son por tanto de amistad y/o vecindad. Esta relación, además, estará motivada por la lógica de la reciprocidad. En consecuencia, el espacio de la comunidad en los sistemas de organización social del cuidado es ocupado o representado por personas que, a título individual y motivadas por la lógica de la reciprocidad, realizan ciertas acciones de cuidado o ejercen una función social/relacional significativa para el bienestar emocional de otras personas.

Si bien es patente la indefinición que acompaña al conepto de comunidad y su carácter difuso en los sistemas de bienestar y cuidado, de forma generalizada, las personas entrevistadas han identificado con claridad el apoyo provisto por vecinos/as y amigos/as como aquel que forma parte de la comunidad. Atendiendo a los resultados, se evidencia que el cuidado es provisto mayoritariamente por las familias, además de los servicios públicos o privados en su caso. A partir de aquí se mencionan también las amistades, los vecinos o la comunidad, pero se reconoce que su función es mucho más residual, especialmente en el caso del vecindario. En el orden de prioridad a la hora de solicitar apoyo o cuidados, encontramos los familiares en primer lugar, los amigos en segundo lugar, servicios públicos o privados en tercer lugar, y los vecinos en cuarto lugar. Díaz Gorfinkel y Pérez Orozco (2011) han señalado también que en España las y los vecinos apenas son señalados dentro de las alternativas de posibles cuidadores, en función de las concepciones de familia e intimidad imperantes $y$, por tanto, la presencia de la comunidad en la asignación de las actividades de cuidado es bastante escasa, realizándose de forma puntual y bajo la rúbrica de favor personal. Tobío et al. (2011) coinciden igualmente con este planteamiento al afirmar que es limitado el cuidado que se ofrece desde las redes no profesionales extrafamiliares.

Antes se daba de una forma muy fácil entre vecinos y vecinas, y ahora tú no esperas que tu vecino te escuche ni se te ocurre contarle nada. (Experto/a-profesional Tercer Sector, FEG2)

Pero, ahora mismo, ahora mismo, yo no veo que a las personas mayores les cuide la comunidad, les cuida su familia, que yo creo que es distinto. Les cuida su familia y les cuidan pues los servicios, bien públicos o bien privados, pero los servicios. Pero luego la comunidad como tal yo creo que no esta interviniendo apenas. (Experto/aacadémico/a, MEG1)

Queda patente que el cuidado es una cuestión familiar, tanto de facto como de iure, y que a este se le reconoce una centralidad incuestionable. Los servicios (públicos o privados) por su parte, tienen también un espacio claramente reconocido, mientras que las amistades se reconocen como importantes fuentes de apoyo. El vecindario, sin embargo, es señalado más como una posibilidad que como una fuente habitual de cuidados. Es, tal y como se ha señalado, una esfera a la que se puede recurrir, pero a la que no siempre se recurre.

Pues la familia aparece evidentemente como fundamental, pero siguen apareciendo ahí los amigos, los vecinos. La mayoría de la gente expresa que sí tienen a alguien a quien recurrir ¿no? (Experto/a-académico/a, MEB1)

Las personas que han participado en el proceso de cocreación arriba descrito apuntan a que las relaciones de cuidado entre vecinos o comunitarias podrían definirse como "escasas", especialmente cuando son comparadas con la realidad que vivieron algunas de las personas participantes cuando eran jóvenes. Podríamos pensar, sin embargo, que esta manifestación puede estar motivada por la nostalgia y cuestionarnos esta idea. Por otra parte, si bien se identifica que las relaciones de cuidado a nivel vecinal no son muy intensas, las personas mayores se muestran en general "satisfechas" con el nivel de relaciones que mantienen con sus vecinos en la actualidad. Se constata por tanto cierta complacencia con lo existente. Los tiempos pasados fueron más amigables y comunitarios, pero tampoco señalan una necesidad imperante de cambiar la realidad.
Ahora en un entorno más urbano eso no se da, no se da de forma tan espontanea como se daba antes. Porque se entiende que hay que tener respeto a la privacidad, no tienes por qué preguntar ni saber con quien estás. Entonces, mantienes una interacción muy pequeña con quienes son tus vecinos o vecinas. $Y$ eso se ha asumido y es un cambio muy rotundo en comparación con lo que podía ocurrir en los años setenta-ochenta. De ahí, se ha ido disminuyendo, aunque hay vecindades que mantienen esa conexión ¿no? (Experto/a profesional tercer sector, FEG2)

Dicho lo cual, y pese a su invisibilización y escasa incidencia, la comunidad parece tener un espacio definido en los sistemas de cuidado, llegando a "muchas cosas de las que la familia no va a llegar, [...] la Administración tampoco va a llegar, ni el mercado tampoco va a llegar" (experto/a académico/a, MEG1). Sabemos, por tanto, que su lugar está allí donde ninguna otra esfera parece llegar (a excepción de la familia, con sus diferencias). Por norma general, se reconoce su espacio en el sistema mayormente relacionado con elementos de cuidado de "baja intensidad”, circunscrito a necesidades dentro del ámbito social y relacional, cumpliendo una función "preventiva”. Recuperando la idea expuesta previamente, uno de los espacios que la comunidad puede ocupar en relación al conjunto del sistema es el de "antena", que necesariamente implica una relación con el resto de esferas. En el contexto en el que se desarrolla esta investigación, la mayor 
parte de esfuerzos políticos o institucionales están orientados precisamente en esta dirección, pero está lejos aún de ser una realidad.

El cuidado informal, a ver, yo creo que mucho está en la prevención, en el facilitar la vida, en el acompañar... Porque, claro, cuando ya entras en problemas de dependencia, los problemas son de otra índole. Yo creo que esta más en el previo, en el "jo, somos todo comunidad, vamos a ayudar, nos vamos a hacer la vida fácil, ¿no?”. (Cargo político, FPOA1)

A este respecto, surge una de las principales ideas que debemos destacar acerca de la comunidad en el sistema de organización social de los cuidados. Esta es la lógica de la "complementariedad" entre la función que las diferentes esferas cumplen, y en especial en lo referente a la comunidad. Atendiendo a esta lógica, las diferentes esferas que participan en la provisión de cuidados cumplen funciones que debieran estar bien diferenciadas, y que difícilmente pueden ser sustituidas. Y se entiende que la función de la comunidad es especialmente "insustituible". Tal y como se ha señalado en esta investigación, si es el sector público o el mercado el que suple una necesidad material, pese a que pudiera tener otra serie de consideraciones, el tipo de apoyo que se da no sufriría una gran variación. Sin embargo, tal y como se ha manifestado en este artículo, "la amistad no se puede comprar". La esfera comunitaria opera precisamente en ese nivel o plano social, en el que introducir la lógica del mercado, o la del derecho, sería una clara anomalía. Indudablemente, una persona que esté siendo atendida por un/a profesional, estará acompañada y puede que se establezca una relación significativa, pero no deja de ser una relación mediada por un contrato y, por ende, con unos tiempos predeterminados y un marco normativo que lo regula. Esto no implica que un cuidado u otro sea ni mejor ni peor, ni más ni menos deseable, sino que a cada uno le corresponde un lugar determinado.

Pero yo no me sonrojo cuando creo que hay que promover todo ese apoyo comunitario. Porque me parece que puede ayudar, pero en ningún caso sustituir ¿no? Y, sobre todo, puede ayudar a las personas a mejorar su calidad de vida, que al final debe ser lo más importante. (Cargo político, MPOG1)

Y en este debate debemos incluir y abordar la cuestión de si la comunidad es un elemento universalizable en los sistemas de cuidado, así como su consideración o no como derecho. Es decir, ¿es la comunidad un recurso disponible y accesible para todas las personas? Más cuando hablamos de promover lo comunitario y de integrarlo en los sistemas de forma que sean un pilar de estos, debemos tener en cuenta que no pueden ser reivindicados en base al derecho, como los servicios públicos, ni comprados en el mercado. Su existencia y la posibilidad de ser integrados en el sistema dependerá de condiciones particulares de cada contexto, y de estrategias y proyectos que requieren un compromiso a largo plazo. Esta cuestión nos lleva a incorporar un segundo elemento, que será el del establecimiento de mecanismos que aseguren un estándar de seguridad y calidad mínima en la provisión, así como la generación de espacios para la relación entre las esferas que participan en la provisión de cuidados y bienestar, que posibiliten lo anteriormente citado.

Y unido al debate de la universalización de la comunidad, tampoco debemos olvidar que la comunidad implica participación, y que no todas las personas están interesadas o tienen la capacidad para hacerlo. Partiendo de la base de que, efectivamente, no todas las personas, y menos aún las personas mayores (especialmente aquellas que se encuentran en situación de fragilidad), tienen la oportunidad, la capacidad o el interés por participar en dinámicas comunitarias, se refuerza la idea de que la comunidad puede tener un espacio bien definido en los sistemas de cuidado, pero debe ser siempre propuesta como complemento, y se deben de reconocer sus límites.

Esto nos lleva a tener que definir una líneas claras de hasta dónde puede o debe llegar cada una de las esferas, especialmente relevante en el caso de la comunidad. De lo contrario, podemos correr el riesgo de que bajo el pretexto de socializar, comunalizar o democratizar ciertas áreas del cuidado, estemos promoviendo en la práctica la privatización o refamiliarización del cuidado. Determinar por tanto qué cuestiones pueden ser resueltas (y cuáles no deberían) en familia, cuáles en la comunidad, y cuántas otras por medio del resto de esferas es un ejercicio necesario. Un ejercicio que desde la academia o las Administraciones Públicas se puede ir fomentando y acompañando, pero que debe ser realizado implicando al conjunto de la sociedad. Establecer los límites y optimizar cada función es un proceso paralelo a su articulación con el resto de esferas, y es una cuestión en la que todas ellas están implicadas.

\subsection{La comunidad en la configuración actual del sistema de servicios sociales en Euskadi}

La reorganización de los esquemas de bienestar y optimizar la función que cumplen las diferentes esferas se ha convertido en un hecho imperativo para dar una respuesta efectiva a las necesidades sociales emergentes. Los riesgos sociales actuales, algunos de ellos de escala planetaria, no pueden ser enfrentados desde una lógica individual ni comunitaria, pero tampoco las instituciones públicas podrán, por sí solas, contener estos riesgos y dar respuesta a las necesidades generadas. Se evidencia la necesidad de trabajar de forma articulada, ubicando en cada nivel las responsabilidades que correspondan. 
Cada vez hay más evidencia de que los servicios públicos que tenemos diseñados no son capaces de responder ante los problemas complejos. 0 sea, este es el gran debate hoy en día en el sector público. 0 sea, la evidencia es total. El diseño de servicios públicos que tenemos hoy en día no es capaz de responder a las necesidades y demandas que plantean los problemas complejos. (Experto/ a-académico/a, MEB4)

Yo sí que pienso que frente a las dinámicas de la globalización y de la fragmentación del territorio y de la segmentación espacial solo las comunidades no pueden hacer nada, solo las decisiones individuales no pueden hacer nada, tienes que funcionar con una política pública. (Experto/aacadémico/a, MEB2)

Los servicios sociales, que son el principal representante de la esfera pública en los sistemas de organización social de los cuidados, se presentan como uno de los principales (si no el principal), agentes en la transición hacia un modelo comunitario y democratizado de cuidados. Las comunidades por sí mismas podrán, efectivamente, poner en marcha dinámicas muy efectivas, pero su alcance será limitado si no se ponen en diálogo con el resto de esferas, y especialmente con las instituciones públicas, teóricas garantes del bienestar de todo individuo. Y es por ello que el sector público adquiere una grán relevancia en este trabajo, a saber, por su responsabilidad y su capacidad para transitar hacia otro modelo. De las instituciones públicas depende, en gran medida, determinar la configuración de los sistemas de organización social del cuidado y contribuir a avanzar en la desfamiliarización y la desmercantilización de los cuidados, promoviendo la consecución de un sistema más justo e igualitario.

El análisis constata la existencia de una voluntad política y un interés profesional y académico respecto a la posibilidad de integrar en mayor medida a la esfera comunitaria en los sistemas de cuidado. Se constata, por tanto, la necesidad de transitar hacia un modelo de cuidado de enfoque comunitario (ya explicitada en la ley $12 / 2008$ de Servicios Sociales de Euskadi), en el que las relaciones comunitarias pudieran tener una función más relevante de la que actualmente tienen. La realidad actual, sin embargo, sigue siendo la de un sistema que no se relaciona ni integra lo comunitario y que plantea serias dificultades para hacerlo. Esto implica que las Administraciones Públicas, y en especial el sistema de servicios sociales, deberían iniciar un proceso de reconfiguración y reestructuración que posibilite esta transición y transformación del sistema de cuidado.

No sé qué creo que has planteado que es, yo creo que sí que hay interés por recuperarlo. Alguna vez hablando con $X$ que sí que hay, lo que no sé es cómo se puede ni orientar ni organizar ni promover, quiero decir desde el Gobierno. Porque tiene que ser de mas cerca y en comunidades pequeñas evidentemente, porque si no... (Profesional-gestor público, FPMA1)
La situación actual del sistema de servicios sociales dibuja un panorama muy complejo en lo referente a su perspectiva comunitaria. Se destacan las dificultades a nivel de los servicios sociales de base (SSB), que son los encargados de la atención primaria y comunitaria, y por tanto asumen una mayor parte de las referencias en el discurso de las personas entrevistadas, pero cabe recordar, que se trata de una pieza del conjunto del sistema, y que, por tanto, deberemos cuestionar el funcionamiento del conjunto del sistema, y no únicamente en de los SSB. De los tres niveles competenciales existentes en Euskadi, el único desde el que se reconoce cierta labor comunitaria es el municipal, pero los resultados muestran que se encuentran en una situación muy compleja para integrar la perspectiva y el enfoque, así como el trabajo comunitario en el sistema. Pese a diferencias y particularidades que se puedan dar a nivel local, el análisis muestra una realidad muy homogénea en cuanto al nivel de integración de la esfera comunitaria en los sistemas de bienestar y cuidado. Tal y como se ha manifestado previamente, la realidad es que la relación de las Administraciones con la esfera comunitaria, así como su integración en los sistemas, es prácticamente nula. Y son varias las razones que se han identificado como determinantes de esta situación. La primera de las cuestiones que se pueden destacar es la orientación individual y asistencialista del sistema, y la sobrecarga de este.

Entonces es verdad que, dentro de las obligaciones, funciones, prestaciones y servicios que ofrecemos desde la Diputación no tenemos ninguna relación con la comunidad. Porque todos nuestros servicios y nuestras obligaciones ya están centrados en personas con dependencia, con discapacidad, en riesgo de exclusión o en riesgo. (Cargo político, MPOG1)

Respecto a lo comunitario, en nuestro país no hay intervención comunitaria. Cuando hablamos de servicios sociales como receptor de demandas y soltador de cosas, no genera mirada de comunidad. [...] No hay trabajo comunitario y no tiene pinta de que vaya a haberlo. No será rescatando lo que había anteriormente, porque eso ya no tiene rescate, sino actualizando al siglo XXI dinámicas de acompañamiento mutuo, de relaciones que han desaparecido. (experto/a-académico/a, MEB5)

Se sabe qué habría que hacer, pero no se esta haciendo nada. (profesional-gestor público, FMPB1)

La gestión de casos y la atención individualizada absorben el tiempo y los recursos disponibles, dejando poco o nada de espacio para el trabajo comunitario. Pese a que la voluntad profesional pueda existir, si no se liberan espacios o se aumentan los recursos disponibles, hoy por hoy, el trabajo comunitario desde los servicios sociales de base se plantea imposible.

En muchos casos no es falta de voluntad, es que el trabajo que tenemos que hacer nos come y 
no tenemos espacios, tiempos para construir. El trabajo nos come. (Experto/a-académico/a, FEG5)

En este momento los servicios sociales en general están muy dirigidos a solventar problemas graves de dependencia, conseguir recursos sobre todo a nivel de dinero y servicios, y no están haciendo ese papel. (Experto/a-profesional Tercer Sector, FEG2)

A nivel práctico qué sucede, que la demanda de atención individual satura todo el tiempo. Entonces tiene que responder a la necesidad urgente, y queda en un segundo plano la intervención comunitaria. Ese es el dilema que tenemos ahora. (Profesional-gestor público, FPMA4)

Quiero decir que, al final, el día a día es brutal. Es decir, la demanda, dar respuesta la demanda es muy complicado. Entonces, al final sí haces intervención, pero haces muy poca. (Cargo político, MPOB2)

Al contrario de lo que en ocasiones parece haberse planteado, integrar a la esfera comunitaria en los sistemas de cuidado no supondrá un ahorro directo para el sistema. No al menos en una fase inicial, en la que las Administraciones deben aumentar los recursos destinados a ello, y poner en marcha todo un conjunto de estrategias para engrasar las relaciones entre la Administración y la esfera comunitaria, así como el desarrollo de diversos planes, programas o proyectos. Cabe debatir si el ahorro generado podría ser de carácter indirecto, especialmente hacia el sistema de salud, en razón de menor número de consultas ambulatorias, y un mayor y mejor control de la salud (mental y física) de las personas mayores, etc.

En este momento necesitaría más recursos, es una inversión. Porque a largo plazo algunos cuidados los proveería la comunidad. Pero esto no es fácil, tenemos que acertar en cómo construimos relaciones significativas nuevas. (Cargo político, MPOB1)

Asimismo, se plantea que la burocratización del sistema es un claro escollo para trabajar a nivel comunitario. Las normativas, los protocolos, procedimientos, estandarización, etc., que caracterizan la acción de las instituciones públicas, aunque necesarias, pueden impedir u obstaculizar el diálogo con la comunidad. La atención y el cuidado que proviene de la esfera pública requieren una profilaxis que contrasta con la realidad comunitaria. La comunidad es, precisamente, lo contrario a la inmunidad que reproduce la profesionalidad. Como la profesionalidad requiere deslindar el plano personal del profesional, el trato que se reproduce debe ser lo más “aséptico" y regulado posible, lo que colisiona con la naturaleza de las relaciones cercanas y personales que se reproducen a nivel comunitario.

La dificultad que yo veo es en poderlo poner en práctica, en tener el tiempo suficiente para llevarlo a cabo. Y creo que es mas fácil responder al modelo de despacho, en el que viene una persona, esta todo reglado... Seguimos con un sistema de prestaciones y los profesionales pueden acomodarse. Es mas fácil, te plantean un problema y les das la respuesta. (profesionalgestor público, FPMA4)

Así, las relaciones dentro de la esfera pública se caracterizan por la rigidez, la imposibilidad de improvisación, y de salirse de los límites marcados por el marco normativo. De hecho, contravenir estas normas y procedimientos pueden ser considerados mala praxis. Con esto no queremos decir que esto no sea deseable ni apropiado, y menos aún en determinadas circunstancias y profesiones, sino que supone una dificultad para el trabajo y la acción comunitaria. Y, si bien un cambio de cultura institucional puede resultar utópico, sí se plantea la necesidad de incorporar espacios y fórmulas de mayor flexibilidad.

Otro de los grandes temas es la existencia de reticencias por parte de los profesionales del ámbito social hacia la idea de integrar a la esfera comunitaria en los sistemas. Cabe aclarar que no todas estas reticencias están fundamentadas en una escasez de recursos, o falta de tiempo, sino que en ocasiones se instalan en un plano ideológico. Tal y como se ha constatado a lo largo de este análisis, aunque no generalizada, existe una corriente de pensamiento que cuestiona el postulado fundamental de este trabajo. Es decir, cuestiona que la Administración Pública tenga que interactuar e integrar a la esfera comunitaria.

En segundo o tercero o último lugar está la importancia de la acción voluntaria, que para mí es esencial cuando hablamos comunidad. Sin embargo, aquí yo veo que hay una cierta reticencia desde los empleados públicos, por decirlo así, a incorporar la acción voluntaria como acción complementaria a la acción pública ¿no? Que yo creo que es una cosa tan fácil de entender, pero a la hora de la practica aquí en muchos sitios yo me encuentro que no se cree en eso. (experto/ a-profesional Tercer Sector, FEG1)

Bueno, te decía que aparentemente no debería tener problemas. Pero es verdad que cuando hemos empezado a intentar impulsarlo desde la Administración, pues hemos visto que no todo el mundo está de acuerdo. [...] Sobre todo por parte de los trabajadores sociales municipales, pues no se acaba de ver, no se entiende o se ve con recelo que, en un plan individualizado, donde la Administración forma parte y donde de alguna manera hay que garantizar que se está prestando un servicio, de repente metamos al vecino del primero. (Cargo político, MPOG1)

Además, un debate que no se puede obviar es que el concepto de comunidad es utilizado desde diversos postulados ideológicos, y su lugar en los sistemas de 
bienestar está sujeto a fuertes controversias. Se ha constatado la existencia de cierto miedo o recelo ante la posibilidad de que el discurso de la comunidad sea en definitiva un eufemismo para ocultar recortes 0 la refamiliarización de determinados riesgos, como puede ser el cuidado. Es indispensable, por tanto, aclarar y delimitar cuál es el espacio que se le desea otorgar a la comunidad en los sistemas de bienestar y cuidado, si lo que se pretende es una expansión de este y no una reducción o recorte. De hecho, un discurso ambiguo y poco elaborado en torno a esta cuestión puede generar fricciones y limitar las adhesiones que la transformación del sistema requiere. Es relevante destacar que estos miedos, lejos de ser infundados, se sostienen en experiencias previas planteadas en países como el Reino Unido o Países Bajos.

Con esas interpretaciones interesadas ante el desmantelamiento de derechos hay que tener mucho cuidado. Es que este trabajo, porque te encuentras con los rojos y "epa chaval, a dónde vas”, y les sale la vena ¿no? Que todo lo comunitario...". (Experto/a-consultor/a, MEB3)

Entonces, ahí sí que puede haber el considerar la comunidad como un agente activo en la prestación, en la atención o en el cuidado de las personas... pues igual para un modelo público en el que todo esta prestado por funcionarios, pues igual le choca más que a un modelo más liberal político socioeconómico en el que se entiende que es una parte más de la comunidad. [...] el otro recelo que suele haber es que si la Administración promueve lo comunitario es para ahorrarse el dinero. Ese es un recelo habitual. (Cargo político, MPOG1)

El énfasis en el carácter complementario de la función de cada una de las esferas y especialmente en la de la comunidad, reside en el convencimiento de que el tipo de apoyo es sustancialmente diferente, pero también en la existencia de cierta preocupación ante la posibilidad de que el reverdecimiento del interés sobre las dinámicas comunitarias no suponga una refamiliarización de los cuidados y una descarga de las responsabilidades de las Administraciones.

Tiene un rol (la comunidad), pero es un rol, digamos, que siempre va a ser complementario a la prestación de servicios [...] y eso tiene que estar medianamente claro. Y yo eso aquí, te confieso que veo un problema que me está empezando a preocupar. (Experto/a-profesional Tercer Sector, FEG1)

La Administración no puede, por tanto, sustituir la labor de la comunidad. Yo creo que no puede, ni debe. (Profesional-gestor público, FPMA4)

Esta reticencia, por tanto, puede deberse por un lado a una visión estatalista de la provisión de bienestar, según la cual toda necesidad social debe ser cubierta con medios públicos. Puede ser igualmente consecuencia de una posición de cautela hacia los riesgos anteriormente citados que puede conllevar el discurso de lo comunitario desde las políticas sociales. Pero puede ser también, tal y como evidencian los resultados, que no se deba a ninguna posición ideológica conscientemente adoptada, sino a una falta de conocimiento y corpus teóricopráctico comunitario. Es decir que, no exista una cultura comunitaria en los servicios sociales, y que se perciba lo comunitario como algo extraño a su quehacer.

Yo creo que no tenemos mucha tradición comunitaria, ni cultura participativa (en los servicios sociales). (Experto/a-académico/a, FEG5)

Porque ya hemos visto que desde los servicios sociales estamos perdidos, por eso queremos impulsar lo que te decía ¿no? Vamos a poner un trabajador social para comunitario. Pero ya nos han dicho las propias trabajadoras sociales, y ¿qué va a hacer? Y ¿cómo va a empezar? 0 sea... (Cargo político, MPOB2)

Y luego sobre todo porque no entendemos el concepto. Lo comunitario lo vemos algo muy global y muy abstracto. No tenemos, no sabemos qué es lo que implica. (Profesional-gestor público, FPMA3)

Es destacable cómo la función de la comunidad en el cuidado es infravalorada e invisibilizada desde un plano social, pero también lo es a nivel profesional y sistémico, siendo un elemento residual en el sistema de cuidados en Euskadi y prácticamente inexistente en los servicios sociales o la sanidad. El estatus que tiene es de categoría teórica, que se reconoce como necesaria en muchos casos, pero difícilmente aplicable, y siempre como complementaria o subsidiaria de los encargos o responsabilidades actualmente vigentes.

Porque no se lo creen (desde las instituciones), no sé cómo decirlo, es como: ¡qué bonito es! Pero que no es bonito, que este proyecto es un reto, un reto social. (Profesional-gestor público, FPMG2)

Yo creo que está ahí en gran.... Es la “maría” de los servicios sociales... (Cargo político, MPOB2)

Esto nos lleva a un debate esencial para los servicios sociales, que es, ni más ni menos, definir cuál es su objeto. Está meridianamente claro que el objeto del sistema sanitario es la salud y que el del sistema educativo es la educación, pero, ¿cuál es el objeto de los servicios sociales? Sin ahondar ahora en este debate, que daría pie a un análisis mucho más exhaustivo del que aquí se precisa, sí es destacable que parece no existir un consenso claro. Lo comunitario es considerado como algo que forma parte del quehacer de los servicios sociales y la práctica del Trabajo Social, pero parece estar instalado en un plano teórico. Es decir, si reparamos 
a la realidad de la práctica en la actualidad, lo comunitario es, cuanto menos, escaso. A la luz de nuestros resultados, esta realidad puede estar contribuyendo a "alejar" ambas esferas, y generando dudas dentro de las propias instituciones y cuerpos profesionales, sobre si realmente debe formar parte o no de su trabajo.

Lo que pasa es que esto es un desiderátum por mi parte. Seguramente si entrevistaras a la inmensa mayoría de las trabajadoras o los trabajadores de esta ciudad, muy pocos tendrían claro que esa es su misión, su encargo. (Experto/a-académico/a, MEB2)

Entender lo comunitario como algo implícito al trabajo social creo que es la esencia en estos momentos y la esencia no es la tramitación, es el acompañamiento de la gente. Y si eso no cambia, el trabajo social va a morir por sí mismo. 0 sea, va a dejar de existir. Porque para ser meros tramitadores de prestaciones... (Profesionalgestor público, FPMA3)

El problema es que ahí no tenemos muy claro cuál es el papel de los servicios sociales y lo que tiene que hacer, una cosa o las dos. (Experto/aacadémico/a, MEG1)

Por el lado opuesto, respecto a la percepción que tiene la ciudadanía acerca de los servicios sociales, se ha señalado la existencia de dos elementos socialmente extendidos: En pimer lugar, el desconocimiento, y en segundo lugar, un cierto estigma. Tal y como se ha señalado a lo largo de la investigación, gran parte de la población desconoce la labor de los servicios sociales, su ubicación, los derechos que les corresponderían, así como el beneficio o la utilidad que podría tener para ellos, entre otras cuestiones. Y, a la vez, se relaciona el sistema mayoritariamente con situaciones de exclusión con las que muchas personas no se reconocen. Esto genera un desapego de determinadas capas sociales, que lo convierte en un sistema para una parte de la población, y no en algo universalmente reconocido como la sanidad o la educación.

Mira, el trabajo social ahora mismo tiene un hándicap también a nivel comunitario. $Y$ es que todo lo que se organiza desde el servicio social de base, ah no, para los pobres no... Porque no hay una trayectoria, porque no hay un recorrido. (Profesional-gestor público, FMPB1)

Yo creo en general si miro el sistema de servicios sociales, creo que se tiene en cuenta un poco lo comunitario en que sean servicios de proximidad. En lo que es el modelo teorico de la ley de servicios sociales sí se hace hincapié, pero luego el desarrollo y la práctica, en general, venimos de un modelo muy asistencialista, y hay que ir transitando hacia otro modelo. (Profesional-gestor público, FPMA2)
La consecuencia de esta realidad es que un proceso promovido desde un departamento de acción social o servicios sociales puede tener dificultades para generar adhesiones. Hablamos, en definitiva, de la crisis de legitimidad que enfrentan muchas instituciones públicas en el contexto actual, que es especialmente visible cuando estas se aproximan a los entornos locales y al diálogo con la ciudadanía. Ante este escenario se propone que la reconfiguración no solo de los servicios sociales y de la práctica del trabajo social, sino también de las formas de gobernanza en conjunto, hacia fórmulas más comunitarias y democráticas podría tener un efecto positivo.

\section{Conclusión}

Nuestros resultados muestran que, si bien el interés y la necesidad por transitar hacia un modelo más comunitario y democrático de cuidados existen, el camino por recorrer es largo y son muchos los obstáculos que deberemos salvar. Debido a la naturaleza difusa del propio concepto, tanto su propia definición como su espacio en los sistemas de cuidado son elementos difíciles de delimitar teóricamente. Asimismo, tanto su función como su espacio en los sistemas de organización social del cuidado pueden definirse a dia de hoy como “escasos". En términos generales, su incidencia es muy reducida, y ocupa un espacio periférico en el conjunto del sistema. Esto supone que, si bien su función y su espacio son reconocidos e identificados como positivos, el impacto que tienen las comunidades en el cuidado es limitado. Existe, además, escaso desarrollo e implementación de estrategias y políticas orientadas al aumento de esta función, y la relación de las Administraciones Públicas con la esfera comunitaria, así como su integración en los sistemas, es prácticamente nula.

Además, resulta determinante resaltar que la forma en la que se entiende y provee el cuidado en Euskadi está profundamente influenciada por un sistema de valores que lo remite al ámbito privado y familiar. Según este ideal, la responsabilidad del cuidado o de dar respuesta a situaciones de dependencia y fragilidad corresponde a las familias, y la oferta de ayuda puede llegar a ser entendida como una intromisión en sus responsabilidades, al ponerse en cuestión su capacidad para cuidar. Además, estas creencias y valores se traducen también en que las propias personas mayores no reconocen de forma abierta su fragilidad y sus necesidades, siendo solo visibles desde la intimidad.

Y, por otro lado, debemos reconocer que existe también una serie de condicionantes estructurales o sistémicos, relacionados con el modelo productivo imperante. Nos referimos a cuestiones como las características del mercado laboral, la precarización del trabajo, la movilidad, la dificultad para la conciliación, etc., que reducen el tiempo disponible para el cuidado (propio y del otro) y también para la 
participación social y comunitaria. En muchos casos, no es que no exista la voluntad de cuidar, sino que no se dan las condiciones materiales para ello.

La “pinza” que ejercen los elementos culturales y estructurales limita el crecimiento del cuidado comunitario, pero entendemos que esto puede revertirse haciendo el trabajo necesario. A este respecto, surge uno de los debates más esenciales en torno a la función y el espacio de la comunidad en los sistemas de organización social del cuidado. Este no es otro que la consideración o no de la comunidad como derecho, y, por tanto, si podemos entender la comunidad como un elemento universalizable.

A día de hoy, la respuesta es que esto está lejos de ser una realidad. Debemos entender la comunidad como un elemento muy valioso para los sistemas de cuidado, pero siempre complementario, cambiante y local. La comunidad podrá ser integrada en los sistemas de cuidado en la medida de lo posible, atendiendo a la casuística específica de cada entorno concreto. Esto no implica que, a través de generalizar el trabajo comunitario y la integración de la esfera comunitaria en los sistemas, no podamos plantear el derecho a la comunidad como un futurible. Podríamos, de hecho, reivindicarlo en la actualidad como una declaración de intenciones, pero la realidad actual nos obliga a ser aún cautelosos.

Sin embargo, la situación se está volviendo insostenible para grandes grupos de personas, y la pandemia de la covid-19 ha venido a poner de manifiesto con toda la crudeza la idea central que venimos desarrollando a lo largo de este trabajo: las familias no pueden (ni deben) responder de forma aislada a las demandas de cuidados que se puedan producir en su seno, de la misma forma que las instituciones públicas no podrán (ni deberán), en su caso, dar respuestas individualizadas a las necesidades que las familias puedan tener. Es necesario por tanto seguir profundizando en el camino hacia la democratización y socialización de los cuidados y en su comprensión como un elemento central de nuestra existencia.

Esto implica repensar cómo queremos vivir, y entender el rol de cada uno/a en la sociedad desde una lógica de derechos, pero también de responsabilidades. Esto supone un cambio de paradigma, mirar el mundo desde otra óptica, como el feminismo viene promoviendo. Hablamos por tanto de una revolución. Añadamos que la revolución no significa sangre, sudor y lágrimas, sino acelerar, intensificar y colectivizar la acción consciente de cambiar ciertas instituciones centrales, a través de lo que Laval y Dardot (2015) denominan “praxis instituyente". La tarea que nos aguarda es precisamente esta, poner en marcha y apoyar iniciativas, proyectos, investigaciones, etc., que exploren formas y fórmulas para democratizar los cuidados y vayan abriendo y ensanchando el camino.

En este sentido, la principal interpelación política e institucional que de aquí se desprende es que, efectivamente, debemos transformas los servicios y la forma en la que actualmente están organizados los sistemas de bienestar y cuidados. Pero no se trata de recuperar un discurso idealizado del Estado que se limite a la defensa de los servicios públicos, sino de modificarlos, abriendo espacios para la participación, deliberación y decisión no solo de los propios profesionales, sino también de los destinatarios de esos servicios y de la ciudadanía en general. La cuestión entonces es saber cómo transformar servicios públicos para hacer de ellos instituciones abiertas, participativas, orientadas a la gestión de lo común y gobernadas democráticamente. De la misma forma, el trabajo social y otras profesiones afines deberían pensarse también desde esta lógica, alejándose de la simplificación teórica y la burocratización de la praxis, y acercándose a la complejidad y creatividad que requiere construir un sistema de bienestar y cuidados acorde con la realidad y las necesidades del siglo XXI. 


\section{Referencias bibliográficas}

BRENNER, J. y HAAKEN, J. (2000): “Utopian thought: Revisioning gender, family, and community", Community, Work \& Family, 3:3, 333-347, <https://doi.org/ 10.1080/13668800020006839>.

CHOWDHURY, M.F. (2015): “Coding, sorting and sifting of qualitative data analysis: debates and discussion”, Qual Quant, 49, 1.135-1.143, https://doi.org/10.1007/s11135-014-0039-2.

COMAS-D’ARGEMIR, D. (2019): “Cuidados y derechos. El avance hacia la democratización de los Cuidados", Cuadernos de Antropología Social, 49, 13-29, shttps://doi.org/10.34096/cas. i $49.6190>$.

DAATLAND, S. (2009): “How to balance generations: solidarity dilemmas in a European perspective", en Edmondson, R. y Von Kondratowitz, H. (Eds.). (2009): Valuing older people: $A$ humanist approach to ageing, 123-138, Bristol, 〈www.jstor.org/stable/j.cttgqgkgr〉.

DALY, M. y LEWIS, J (2000): "The Concept of Social Care and the Analysis of Contemporary Welfare States", The British Journal of Sociology, 51 (2), 281-298.

DEL PINO y RUBIO (eds.) (2016): Los estados de bienestar en la encrucijada. Políticas sociales en perspectiva comparada, Madrid, Tecnos.

DEUSDAD, B.; Pace, C. y ANTTONEN, A. (2016): “Introduction. Facing the challenges in the development of Long-term Care for older people in Europe in an economic crisis context”, Journal of Social Service Research, 42 (2), 144-150.

DÍAZ GORFINKIEL, M. y PÉREZ-OROZCO, A. (2011): La organización social de los cuidados y vulneración de derechos en España, ONU mujeres, Entidad de las Naciones Unidas para la Igualdad de Género y el Empoderamiento de las Mujeres. Santo Domingo.
DURAN, M. (2017): “Ciudades que cuidan”, en, Nieves, M. y Segovia, O. (eds.), ¿Quién cuida en la ciudad? Aportes para políticas urbanas de igualdad, 91-116, Santiago de Chile, CEPAL.

ESCALANTE, E. (2009): "Perspectivas en el análisis cualitativo”, Theoria, vol. 18 (2), 55-67.

ESPING-ANDERSEN, G. y PALIER, B. (2011): Los tres grandes retos del Estado de bienestar, Barcelona, Ariel.

ESPING-ANDERSEN, G. (1990): The three worlds of Welfare capitalism, New Jersey, Princeton University Press.

FANTOVA, F. (2014): Diseño de políticas sociales, Madrid, CCS.

FINE, M. y GLENDINNING, C. (2005): “Dependence, independence or interdependence? Revisiting the concepts of 'care' and 'dependency", Ageing \& Society, 25 (4), 601-621.

GARDNER, P. (2011): “Natural neighborhood networks Important social networks in the lives of older adults aging in place", Journal of Aging Studies, vol. 25, 3, 263-271, 〈https://doi.org/10.1016/j. jaging.2011.03.007>.

HERRERA, M. (2001): “Las políticas sociales en el Welfare Mix”, Reis: Revista española de investigaciones sociológicas, 96, 71-94.

HERRERO, Y. (2013): “Miradas ecofeministas para transitar a un mundo justo y sostenible", Revista de economía crítica, 16, 278-307.

KUCKARTZ, U. (2014): Qualitative text analysis: A guide to methods, practice \& using software, SAGE Publications, <https://www.doi. org/10.4135/9781446288719>.

LAVAL, C. y DARDOT, P. (2015): Común. Ensayo sobre la revolución en el siglo XXI, Barcelona, Gerdisa. 
LEE, J.; CHAE, J. y LIM, S. (2016): “Governing a Welfare Mix: Operation of Long-Term Care Policies in England and South Korea", Korea Observer, vol. 47, 1, 167-197.

LLENA, A.; PARCERISA, A. y Ucar, X. (2009): 10 ideas clave: La acción comunitaria. Barcelona, Graó.

LONGO, F.; NOTARNICOLA, E. y TASSELI, S. (2015): “A framework to assess welfare mix and service provision models in health care and social welfare: case studies of two prominent Italian regions", BMC Health Services Research, 15, $152<$ https://www.doi.org/10.1186/s12913-0150800-9>.

MAINO, F. (2015): “El segundo welfare entre innovación e inversión social: ¿cuáles son las respuestas a la crisis del Estado social?", en BRONZO, Z. y REPPETO, F., Coordinación de políticas sociales: desafíos para la gestión pública, Eurosocial, no $18,105-134$

MORENO-COLOM, S. (2018): “La acción comunitaria y los cuidados a domicilio", en VEGA-SOLís, C., MARTÍNEZ-BUJÁN, R. y PAREDES, M., (eds.): Cuidado, comunidad y común. Experiencias cooperativas en el sostenimiento de la vida, 147-166, Traficantes de Sueños, Madrid.

- (2019): El desafío de género en los cuidados de la vejez, VIII Informe Foessa, documento de trabajo 2.7.

MAŽEIKIEN , N.; NAUJANIEN , R. y RUŠKUS, J. (2014): “What is mixed in welfare mix? Welfare ideologies at stake in the Lithuanian case of social service delivery", European Journal of Social Work, 17, 5, 641-655, <https://www.doi.org/10.1080/136 91457.2014.930732>.

OOSTERLYNCK, S.; KAZEPOV, Y.; NOVY, A.; COOLS, P.; WUKOVITSCH, F.; SARIUS, T. y LEUBOLT, B. (2013): "Exploring the multi-level governance of welfare provision and social innovation: welfare mix, welfare models and rescaling", ImPRovE Discussion Papers, (13/12), 1-44, http://ideas. repec.org/p/hdl/improv/1312.html.

PASTOR, E. (2001): "Iniciativa social y trabajo social comunitario", Alternativas, Cuadernos de Trabajo Social, 9, 169-191.

PESTOFF, V. (1998): Beyond the market and state: Social enterprises and civil democracy in a welfare society, Aldershot, Ashgate.

PRIETO, C. y SERRANO, A. (2013): "Los cuidados entre el trabajo y la vida", Cuadernos de Relaciones Laborales, vol. 31, núm. 1, 11-16.

RAZAVI, S. (2007): The political and social economy of care in a development context conceptual issues, research questions and policy options, Ginebra, Gender and development programme paper, 3, United Nations Research Institute for Social Development.

RENDUELES, C. (2014): "Emancipación, cuidado y codependencia", ISEGORIA, Revista de Filosofía Moral y Política, 50, 167-187, <https://www.doi. org/10.3989/isegoria.2014.050.09>.

RODRÍGUEZ-CABRERO, G. y MARBÁN, V. (2016): “La atención a la dependencia en una perspectiva europea: de la asistencialización a la cuasiuniversalización", en DEL PINO, E. y RUBIO, M. (eds.), Los estados de bienestar en la encrucijada. Políticas sociales en perspectiva comparada, 317-338, Madrid, Tecnos.

RUIZ OLABUÉNAGA, J. (2012): Metodología de la Investigación Cualitativa, Bilbao, Universidad de Deusto.

SENNET, R. (2019): Construir y habitar, Barcelona, Anagrama.

TOBÍO, C.; AGULLó, M.; GÓMEZ, M. y MARTín, M. (2010): El cuidado de las personas. Un reto para el siglo XXI, Barcelona, Fundación La Caixa.

TORNS, T. (2013): "Los cuidados y la vida cotidiana”, en Gilligan, C. (ed.): La ética del cuidado, 86-96, Barcelona, Fundació Víctor Grífols i Lucas.

TRONTO, J. (2013): Caring Democracy: Markets, Equality, and Justice, New York, London, NYU Press, <http:// www.jstor.org/stable/j.cttgqgfvp〉.

VEGA-SOLÍS, C. y MARTÍNEZ-BUJÁN, R. (2017): “Explorando el lugar de lo comunitario en los estudios de género sobre sostenibilidad, reproducción y cuidados, QUADERNS-E, 22 (2), 65-81.

VEGA-SOLÍS, C.; MARTÍNEZ-BUJÁN, R. y PAREDES, M. (2018): Cuidado, comunidad y común. Experiencias cooperativas en el sostenimiento de la vida, Traficantes de Sueños, Madrid.

ZUBERO, I. (2018): "Envejecimiento activo y participación política”, Aula Abierta, 47, 1, 21-28, https://doi. org/10.17811/rife.47.1.2018.21-28.

ZUÑIGA, M. (2020): “La comunidad del Siglo XXI. Un marco interpretativo desde el Trabajo Social", Cuadernos de Trabajo Social, 33 (2), 197-207.

ZUÑIGA, M.; SALABERRIA, E. y ARRIETA, F. (2020): “An analysis of the role of communities in care systems co-created with older people", Public Management Review, 22, 12, 1.799-1.818, 〈https://www.doi.org/10.1080/14719037.2019 .1648699>. 
Perfiles y códigos de las personas entrevistadas

\begin{tabular}{|c|c|c|c|}
\hline Cargo-posición & Sexo & Territorio & Código \\
\hline Cargo político & M & Bizkaia & MPOB1 \\
\hline Cargo político & $\mathrm{F}$ & Araba & FPOA 1 \\
\hline Cargo político & M & Bizkaia & MPOB2 \\
\hline Cargo político & M & Gipuzkoa & MPOG1 \\
\hline Experto/a- Académico & M & Gipuzkoa & MEG1 \\
\hline Experto/a- Académico & M & Bizkaia & MEB1 \\
\hline Experto/a- Académico & M & Bizkaia & MEB4 \\
\hline Experto/a- Académico & $\mathrm{F}$ & Gipuzkoa & $\mathrm{FEG}_{5}$ \\
\hline Experto/a- Académico & M & Bizkaia & MEB5 \\
\hline Experto/a- Consultor & M & Bizkaia & MEB2 \\
\hline Experto/a- Consultor & M & Bizkaia & MEB3 \\
\hline Experto/a- Profesional Tercer Sector & $\mathrm{F}$ & Bizkaia & FEB1 \\
\hline Experto/a- Profesional Tercer Sector & $\mathrm{F}$ & Bizkaia & FEB2 \\
\hline Experto/a- Profesional Tercer Sector & $\mathrm{F}$ & Gipuzkoa & FEG2 \\
\hline Experto/a- Profesional Tercer Sector & M & Gipuzkoa & MEG2 \\
\hline Experto/a- Profesional Tercer Sector & $\mathrm{F}$ & Gipuzkoa & $\mathrm{FEG}_{3}$ \\
\hline Experto/a- Profesional Tercer Sector & $\mathrm{F}$ & Bizkaia & $\mathrm{FEB} 3$ \\
\hline Experto/a- Profesional Tercer Sector & $\mathrm{F}$ & Gipuzkoa & $\mathrm{FEG}_{4}$ \\
\hline Experto/a- Profesional Tercer Sector & $\mathrm{F}$ & Gipuzkoa & FEG1 \\
\hline Experto/a- Profesional Tercer Sector & $\mathrm{F}$ & Gipuzkoa & $\mathrm{FEG}_{5}$ \\
\hline Gestor público & $\mathrm{F}$ & Gipuzkoa & FPMG1 \\
\hline Gestor público & $\mathrm{F}$ & Gipuzkoa & FPMG 2 \\
\hline Gestor público & $\mathrm{F}$ & Bizkaia & FMPB1 \\
\hline Gestor público & $\mathrm{F}$ & Araba & FPMA1 \\
\hline Gestor público & $\mathrm{F}$ & Bizkaia & FMPB2 \\
\hline Gestor público & $\mathrm{F}$ & Araba & FPMA2 \\
\hline Gestor público & $\mathrm{F}$ & Gipuzkoa & $\mathrm{FPMG}_{3}$ \\
\hline Gestor público & $\mathrm{F}$ & Araba & $\mathrm{FPMA}_{3}$ \\
\hline Gestor público & $\mathrm{F}$ & Araba & FPMA4 \\
\hline
\end{tabular}

